\title{
Selection Influences Heritability Estimates and Variance Components for Anthracnose Resistance in Populations Derived from an Intraspecific Cross of Tomato
}

\author{
John R. Stommel ${ }^{1}$ \\ U.S. Department of Agriculture, Agricultural Research Service, Vegetable Laboratory, Plant Sciences \\ Institute, Beltsville, MD 20705
}

\begin{abstract}
AdDitional Index words. Colletotrichum sp., disease resistance, genetics, inheritance, Lycopersicon esculentum, vegetable breeding
\end{abstract}

\begin{abstract}
Aвstract. Genetic characterization of anthracnose resistance in tomato (Lycopersicon esculentum Mill.) caused by Colletotrichum coccodes (Wallr.) Hughes was accomplished using populations developed from crosses between the anthracnose susceptible cultivar US28 and three resistant breeding lines (115-4, 625-3, and 88B147) that varied in their degree of anthracnose resistance and relative stage of adaptation for commercial use. These lines were of common parental lineage with resistance derived from the small-fruited $L$. esculentum USDA PI 272636. Anthracnose lesion diameters and fruit weight were measured in puncture inoculated fruit of parental, $F_{1}, F_{2}$, and backcross generations within each cross. Correlation coefficients between fruit size and lesion diameter were low and generally nonsignificant. Estimates of broad and narrow sense heritabilities for resistance were moderate and declined as relative anthracnose susceptibility of the resistant parent increased coincident with increasing horticultural adaptation. A simple additive dominance model, $\mathbf{m}[\mathrm{d}][\mathbf{h}]$, was adequate to explain the genetic variance for anthracnose resistance in all crosses. Genetic variance for anthracnose resistance was primarily additive. The minimum number of effective factors or loci conditioning anthracnose resistance declined during attempts to transfer high levels of resistance from PI 272636 into adapted breeding lines.
\end{abstract}

Anthracnose is a serious disease of tomatoes (Lycopersicon esculentum) grown in North America for processing. It is endemic in production regions of the northeast and midwestern United States and south-central Canada (Barksdale et al., 1972; Illman et al., 1959). This tomato fruit rot disease is caused primarily by Colletotrichum coccodes (Wallr.) Hughes but can also be elicited by a number of other Colletotrichum sp. including C. dematium (Pers.) Grove and C. gloeosporioides (Penz.) Penz. and Sacc. in Penz. (Barksdale, 1972). Rainfall, warm temperatures, and high humidity which commonly occur at harvest favor disease development (Sanogo et al., 1997). Genetic resistance to anthracnose is desirable because cultural techniques, which include fungicide application, crop rotation, and elimination of alternate hosts, provide incomplete protection from this fungal fruit rot pathogen (Byrne et al., 1997; Dillard and Cobb, 1998).

High levels of genetic resistance to anthracnose exist in wild or unadapted tomato germplasm, but this resistance has been difficult to transfer into elite materials with an intensity equal to that observed in the wild donor parent (Barksdale and Stoner, 1975; Stommel and Haynes, 1998). Breeding lines with moderate levels of anthracnose resistance have been developed by the U.S. Department of Agriculture (USDA), and commercial cultivars with varying but lesser levels of resistance are available (Byrne et al., 1997; Stevenson et al., 1978). Difficulty in transferring the high level of resistance observed in small-fruited germplasm to commercial type lines may be attributed in part to the occurrence of multiple genetic factors, each with a relatively small effect, which influence resistance. Previous studies of anthracnose resistance in tomato demonstrated a polygenic mode of inheritance (Ng et al., 1990; Robbins and Angel, 1970a; Stommel and Haynes, 1998).

Received for publication 10 Aug. 2000. Accepted for publication 13 Mar. 2001. The cost of publishing this paper was defrayed in part by the payment of page charges. Under postal regulations, this paper therefore must be hereby marked advertisement solely to indicate this fact.

${ }^{1}$ E-mail: stommelj@ba.ars.usda.gov.
A reduced level of anthracnose resistance was evident in largefruited breeding lines developed from the unadapted, small fruited, highly resistant L.esculentum accession USDAPI272636(Stommel and Haynes, 1998). The objectives of the present study were to assess the genetic effects that contribute to $C$. coccodes resistance in PI 272636 and evaluate the potential loss of genetic resistance factors that may have occurred during development of elite breeding lines or cultivars.

\section{Materials and Methods}

Plant materials. $F_{1}, F_{2}$, and backcross $\left(F_{1}\right.$ backcrossed to $P_{1}$ or $\mathrm{P}_{2}$ ) generations were developed from crosses between the anthracnose susceptible cultivar US28 and the resistant inbred L. esculentum breeding lines 115-4, 625-3, and 88B147, respectively. The resistant breeding lines were chosen to develop the respective populations based upon their common parental lineage, level of anthracnose resistance, and their varying degree of adaptation for commercial use. Line 115-4 is a small-fruited, resistant selection from L. esculentum $\mathrm{PI} 272636$. Line $625-3$ is a $\mathrm{BC}_{1} \mathrm{~F}_{5}$ resistant line with intermediate size fruit selected from a population developed from the initial cross between the susceptible cultivar Roma X 1154 backcrossed to 115-4. Line 88B147 is an adapted breeding line with commercial size fruit developed for its anthracnose resistance and released by the USDA (T.H. Barksdale, personal communication). Its pedigree is complex and includes line 625-3. US28 is a processing cultivar chosen for susceptibility to anthracnose. The respective populations were developed by crossing greenhousegrown plants using standard emasculation practices. Progeny of each population were field-grown at Beltsville, Maryland, in Keyport fine loam soil, a clayey, mixed, mesic Acquic Hapludult, using standard cultural practices as described previously (Stommel and Haynes, 1998). The experimental design was a modified split plot with two replications with mating series occupying whole plots and generations within series occupying split plots. Plants were distributed equally among subplots. The total number of plants evaluated 
Table 1. Anthracnose lesion diameters (mean $\pm \mathrm{SE}$ ), fruit weights (mean $\pm \mathrm{SE}$ ), and correlation coefficients $(r)$ between lesion size and tomato fruit weight in parental, $\mathrm{F}_{1}, \mathrm{~F}_{2}$, and backcross generations from the Lycopersicon esculentum cross US28 x 115-4, 625-3, and 88B147, respectively.

\begin{tabular}{|c|c|c|c|c|}
\hline Generation $^{\mathrm{z}}$ & $\begin{array}{c}\text { Plants } \\
\text { (no.) } \\
\text { (n) }\end{array}$ & $\begin{array}{l}\text { Lesion diam }{ }^{\mathrm{y}} \\
(\mathrm{mm})\end{array}$ & $\begin{array}{l}\text { Fruit } w^{t^{y}} \\
\qquad(g)\end{array}$ & $r^{\mathrm{x}}$ \\
\hline \multicolumn{5}{|c|}{$\overline{\mathrm{US} 28 \times 115-4}$} \\
\hline $\mathrm{P}_{1}$ & 9 & $15.8 \pm 1.3$ & $105.8 \pm 3.9$ & \\
\hline $\mathrm{P}_{2}$ & 10 & $1.4 \pm 0.4$ & $13.3 \pm 0.7$ & \\
\hline $\mathrm{F}_{1}^{2}$ & 10 & $7.8 \pm 1.9$ & $39.6 \pm 1.1$ & $-0.125^{\mathrm{NS}}$ \\
\hline $\mathrm{F}_{2}$ & 73 & $8.2 \pm 0.7$ & $39.7 \pm 1.3$ & $0.197^{\mathrm{NS}}$ \\
\hline $\mathrm{BC}_{1} \mathrm{P}_{1}$ & 24 & $11.0 \pm 1.3$ & $70.9 \pm 3.3$ & $-0.426^{*}$ \\
\hline $\mathrm{BC}_{1} \mathrm{P}_{2}$ & 24 & $3.7 \pm 0.7$ & $22.6 \pm 1.4$ & $0.153^{\mathrm{NS}}$ \\
\hline \multicolumn{5}{|l|}{$\mathrm{US} 28 \times 625-3$} \\
\hline $\mathrm{P}_{1}$ & 9 & $15.8 \pm 1.3$ & $105.8 \pm 3.9$ & \\
\hline $\mathrm{P}_{2}$ & 10 & $3.1 \pm 1.0$ & $40.9 \pm 7.2$ & \\
\hline $\mathrm{F}_{1}^{2}$ & 10 & $11.0 \pm 1.7$ & $48.9 \pm 2.5$ & $0.312^{\mathrm{NS}}$ \\
\hline $\mathrm{F}_{2}$ & 75 & $8.5 \pm 0.7$ & $59.4 \pm 1.8$ & $0.292^{*}$ \\
\hline $\mathrm{BC}_{1} \mathrm{P}_{1}$ & 24 & $14.0 \pm 1.2$ & $81.0 \pm 3.7$ & $0.018^{\mathrm{NS}}$ \\
\hline $\mathrm{BC}_{1} \mathrm{P}_{2}$ & 23 & $8.1 \pm 1.1$ & $49.5 \pm 1.9$ & $0.001^{\mathrm{NS}}$ \\
\hline \multicolumn{5}{|c|}{ US $28 \times 88 B 147$} \\
\hline $\mathrm{P}_{1}$ & 9 & $15.8 \pm 1.3$ & $105.8 \pm 3.9$ & \\
\hline $\mathrm{P}_{2}$ & 10 & $10.5 \pm 1.6$ & $66.3 \pm 1.8$ & \\
\hline $\mathrm{F}_{1}^{2}$ & 10 & $14.6 \pm 1.4$ & $114.7 \pm 9.2$ & $0.221^{\mathrm{NS}}$ \\
\hline $\mathrm{F}_{2}$ & 74 & $13.4 \pm 0.6$ & $104.0 \pm 4.0$ & $0.097^{\mathrm{NS}}$ \\
\hline $\mathrm{BC}_{1} \mathrm{P}_{1}$ & 24 & $12.9 \pm 1.0$ & $92.6 \pm 3.7$ & $0.331^{\mathrm{NS}}$ \\
\hline $\mathrm{BC}_{1} \mathrm{P}_{2}$ & 23 & $9.9 \pm 1.0$ & $86.3 \pm 2.8$ & $-0.001^{\mathrm{NS}}$ \\
\hline
\end{tabular}

${ }^{\mathrm{Z}} \mathrm{P}_{1}=$ susceptible parent, US28; $\mathrm{P}_{2}=$ resistant parent, 115-4, 625-3, and 88B147, respectively.

yPopulation lesion diameters and fruit weights are the average for n number of plants. Estimates for each plant are the mean for five weighed and inoculated fruit.

${ }^{x}$ Linear correlation coefficient between lesion diameter and fruit size in each respective generation.

Ns, ${ }^{*}$ Nonsignificant or significant at $P=0.05$, respectively.

is shown in Table 1. Five fruit from each plant of the respective generations within each cross were harvested at the red-ripe stage of development before inoculation with C. coccodes for evaluation of anthracnose resistance. Fruit fresh weights were recorded before inoculation for determination of correlations between lesion diameter and fruit weight.

INOCULATION AND DISEASE EVALUATION. Ripe fruit were placed on shaded greenhouse benches the day of harvest and inoculated by placing a droplet of $C$. coccodes inoculum suspension $\left(5 \times 10^{6}\right.$ conidia $/ \mathrm{mL}$ ) on the fruit and puncturing through the droplet with a needle to a depth of $\approx 2 \mathrm{~mm}$ (Barksdale and Koch, 1969; Robbins and Angell, 1970b). Culture maintenance and inoculum preparation have been described (Stommel and Haynes, 1998). Control fruit were inoculated with distilled water. Daytime greenhouse temperatures of $28 \pm 4{ }^{\circ} \mathrm{C}$ and a minimum nighttime temperature of $18^{\circ} \mathrm{C}$ were maintained. Six days after inoculation, fruit lesion diameters $(\mathrm{mm})$ were measured.

Genetic analysis of GENE ACTION. Two methods of analysis were utilized to evaluate gene action in the respective crosses. The first method utilized generation means analysis as described by Mather and Jinks (1982). Best fit models were developed to describe the genetic components influencing anthracnose resistance. Lesion size and three separate transformations of lesion size (logarithm, natural logarithm, and square root) were evaluated in the analysis. The nontransformed lesion size analysis is reported because it produced the largest $R^{2}$ values in the best-fit models and the lowest sum of squared residuals in comparison to the transformed data. Generation means and their expectations were weighted by the inverse of the variances of the population means. The six generations available for each cross enabled testing of models with up to five parameters for estimation of additive [d], dominance [h], additive $\times$ additive [i], additive $\times$ dominance [j], and dominance $\times$ dominance [l] effects. A simple additive dominance model $(\mathrm{m}[\mathrm{d}][\mathrm{h}])$ and more complex four $(\mathrm{m}[\mathrm{d}][\mathrm{h}][\mathrm{i}], \mathrm{m}[\mathrm{d}][\mathrm{h}][\mathrm{j}]$ and $\mathrm{m}[\mathrm{d}][\mathrm{h}][\mathrm{l}])$ and five parameter $(\mathrm{m}[\mathrm{d}][\mathrm{h}][\mathrm{i}][\mathrm{j}]$ and $\mathrm{m}[\mathrm{d}][\mathrm{h}][\mathrm{i}][\mathrm{l}])$ models with nonallelic interactions or epistatic effects were evaluated. Consistent with criteria set forth by Mather and Jinks (1982), the simplest model that fit the data was accepted, based on a chi-square test with $P>0.05$, despite the possibility that a more complex model exhibited a lower chi-square or higher probability.

The second method of analysis used to describe gene action involved comparison of observed $\mathrm{F}_{2}$ means and theoretical arithmetic and geometric $\mathrm{F}_{2}$ means in the respective crosses (Burton, 1951). Theoretical arithmetic and geometric $F_{2}$ means were calculated using the formula:

Theoretical arithmetic $\mathrm{F}_{2}$ mean $=\left[\mathrm{P}_{1}+2 \mathrm{~F}_{1}+\mathrm{P}_{2}\right] / 4$

Theoretical geometric $\mathrm{F}_{2}$ mean $=$ antilogarithm $\left\{\left[\log \mathrm{P}_{1}+2 \log \mathrm{F}_{1}\right.\right.$ $\left.\left.+\log \mathrm{P}_{2}\right] / 4\right\}$

where $\mathrm{P}_{1}, \mathrm{P}_{2}$, and $\mathrm{F}_{1}=$ mean of $\mathrm{P}_{1}, \mathrm{P}_{2}$ and $\mathrm{F}_{1}$ generation, respectively. Agreement between observed and theoretical arithmetic $\mathrm{F}_{2}$ means suggests additive gene action. Agreement between observed and theoretical geometric $\mathrm{F}_{2}$ means is indicative of nonadditive gene action.

The degree of dominance (h) for genetic factors which influenced anthracnose resistance was calculated using the formulas described by Petr and Frey (1966) and Kotecha and Zimmerman (1978):

$\mathrm{h}_{1}=\left(\mathrm{F}_{1}-\mathrm{mp}\right) /(\mathrm{hp}-\mathrm{mp})$

$\mathrm{h}_{2}=\left[2\left(\mathrm{~F}_{2}-\mathrm{mp}\right)\right] /(\mathrm{hp}-\mathrm{mp})$

where $F_{1}$ and $F_{2}=$ means of $F_{1}$ and $F_{2}$ generations, $\mathrm{mp}=$ midparent mean, and $\mathrm{hp}=$ high parent mean. 

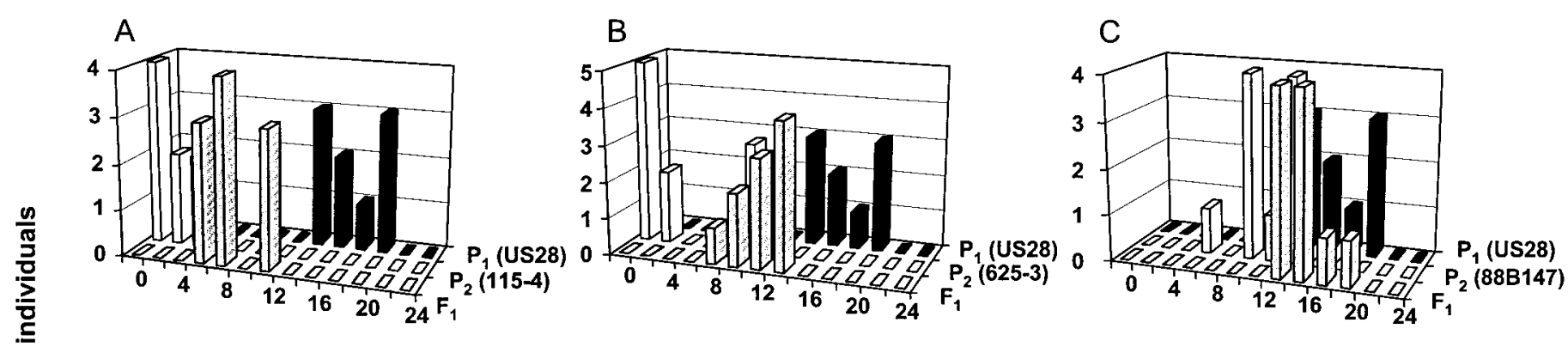

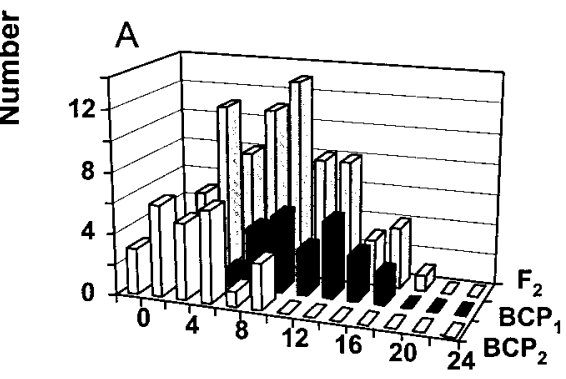

Lesion diameter $(\mathrm{mm})$

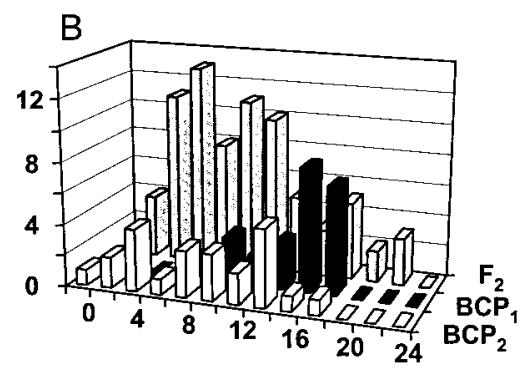

Lesion diameter $(\mathrm{mm})$

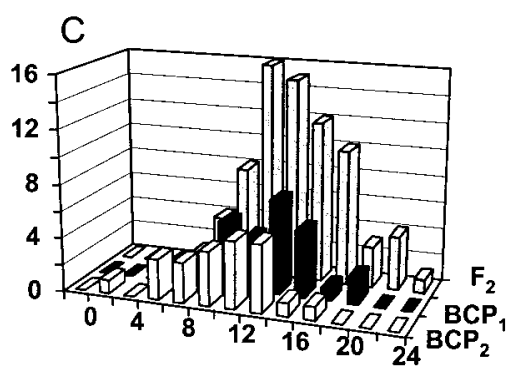

Lesion diameter $(\mathrm{mm})$

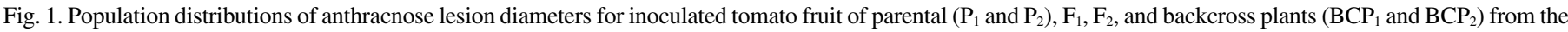

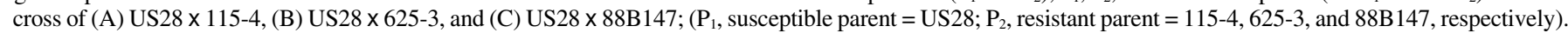

Heritability AND Gene number. Broad sense heritability estimates $(\mathrm{H})$ were calculated as the ratio of the genotypic variance over the phenotypic variance of the $\mathrm{F}_{2}$ generation (Globerson et al., 1987; Kotecha and Zimmerman, 1978):

$\mathrm{H}=\left\{\mathrm{V}_{\mathrm{F} 2}-\left[1 / 3\left(\mathrm{~V}_{\mathrm{P} 1}+\mathrm{V}_{\mathrm{P} 2}+\mathrm{V}_{\mathrm{F} 1}\right)\right]\right\} / \mathrm{V}_{\mathrm{F} 2}$

Narrow sense heritability $\left(\mathrm{h}^{2}\right)$ was estimated using $\mathrm{F}_{2}$ and backcross generation variance components as described by Mather (1949) and Warner (1952):

$\mathrm{h}^{2}=\left[2 \mathrm{~V}_{\mathrm{F} 2}-\left(\mathrm{V}_{\mathrm{B} 1}-\mathrm{V}_{\mathrm{B} 2}\right)\right] / \mathrm{V}_{\mathrm{F} 2}$
For broad and narrow sense heritability formulas, $\mathrm{V}_{\mathrm{P} 1}, \mathrm{~V}_{\mathrm{P} 2}, \mathrm{~V}_{\mathrm{F} 1}, \mathrm{~V}_{\mathrm{F} 2}$ = variance of $\mathrm{P}_{1}(\mathrm{US} 28$; susceptible parent $), \mathrm{P}_{2}(115-4,625-3$, or 88B147; respective resistant parents), $\mathrm{F}_{1}$, and $\mathrm{F}_{2}$ generations, respectively. $\mathrm{V}_{\mathrm{B} 1}$ and $V_{B 2}=$ variance of the $F_{1}$ backcrossed to $P_{1}$ and $P_{2}$, respectively.

An estimate of the number of genetic factors (n) segregating for anthracnose resistance in $\mathrm{F}_{2}$ and backcross generations of the respective mating series was estimated using the formulas derived by Wright (1968):

backcross: $\mathrm{n}=\left(\mathrm{P}_{1}-\mathrm{P}_{2}\right)^{2} / 4\left[\mathrm{~V}_{\mathrm{B} 1}-\left(\left(\mathrm{V}_{\mathrm{P} 1}+\mathrm{V}_{\mathrm{F} 1}\right) / 2\right)\right.$

Table 2. Estimates of broad and narrow sense heritability, degree of dominance, number of genetic factors segregating for anthracnose resistance, and genetic effects derived from the best fit model $\mathrm{m}[\mathrm{d}][\mathrm{h}]$ in the Lycopersicon esculentum populations developed from initial crosses of US28 $\mathrm{x} 115$ 4, US28 x 625-3, and US28 x 88B147.

\begin{tabular}{|c|c|c|c|}
\hline \multirow[b]{2}{*}{ Parameter } & \multicolumn{3}{|c|}{ Cross } \\
\hline & US28 $\times 115-4$ & US28 $\times 625-3$ & US28 $\times 88 \mathrm{~B} 147$ \\
\hline Broad sense heritability (H) & 0.50 & 0.54 & 0.26 \\
\hline Narrow sense heritability $\left(h^{2}\right)$ & 0.41 & 0.36 & 0.23 \\
\hline Midparent $(\mathrm{m} \pm \mathrm{SE})$ & $7.8 \pm 0.3$ & $9.8 \pm 0.7$ & $12.9 \pm 0.6$ \\
\hline$t$ test probability value & 0.0001 & 0.0007 & 0.0002 \\
\hline Additive effect $([\mathrm{d}] \pm \mathrm{SE})$ & $7.3 \pm 0.4$ & $6.2 \pm 1.0$ & $2.9 \pm 1.2$ \\
\hline$t$ test probability value & 0.0003 & 0.0093 & 0.0973 \\
\hline Dominance effect $([\mathrm{h}] \pm \mathrm{SE})$ & $-1.6 \pm 0.8$ & $1.0 \pm 2.2$ & $0.7 \pm 2.4$ \\
\hline$t$ test probability value & 0.1356 & 0.6748 & 0.7803 \\
\hline Arithmetic mean $\mathrm{F}_{2}$ & 8.2 & 10.2 & 13.9 \\
\hline Geometric mean $\mathrm{F}_{2}$ & 6.1 & 8.8 & 13.7 \\
\hline Observed mean $\mathrm{F}_{2}$ & 8.2 & 8.5 & 13.4 \\
\hline Degree of dominance $\left(h_{1}\right)^{z}$ & -0.11 & 0.24 & 0.55 \\
\hline Degree of dominance $\left(h_{2}\right)$ & -0.11 & -0.30 & 0.19 \\
\hline \multicolumn{4}{|c|}{ Minimum no. of genetic factors $(n)^{y}$} \\
\hline Backcross population & 3.3 & 2.7 & 1.1 \\
\hline $\mathrm{F}_{2}$ population & 2.2 & 1.1 & 0.6 \\
\hline
\end{tabular}

${ }^{\bar{z}}$ Degree of dominance $h_{1}$ and $h_{2}$ estimated according to the methods of Petr and Frey (1966) and Kotecha and Zimmerman (1978), respectively.

${ }^{y}$ Minimum number of genetic factors ( $\mathrm{n}$ ) segregating for anthracnose resistance in $\mathrm{F}_{2}$ and backcross populations estimated according to the formulas of Wright (1968). 
Table 3. Genetic models for anthracnose fruit lesion diameter in Lycopersicon esculentum populations developed from the cross of US28 $\times 115-4,625$ 3 , and 88B147, respectively.

\begin{tabular}{|c|c|c|c|c|c|}
\hline Cross & Model $^{\mathrm{z}}$ & $\chi^{2}$ & $\chi^{2}$ critical & $R^{2}$ & $\mathrm{~s}^{2}$ \\
\hline \multirow[t]{6}{*}{$\overline{U S} 28 \times 115-4$} & $\mathrm{~m}[\mathrm{~d}][\mathrm{h}]$ & 1.17 & 7.81 & 0.99 & 0.39 \\
\hline & $\mathrm{m}[\mathrm{d}][\mathrm{h}][\mathrm{i}]$ & 1.13 & 5.99 & 0.99 & 0.57 \\
\hline & $\mathrm{m}[\mathrm{d}][\mathrm{h}][\mathrm{j}]$ & 0.92 & 5.99 & 0.99 & 0.46 \\
\hline & $\mathrm{m}[\mathrm{d}][\mathrm{h}][\mathrm{l}]$ & 0.92 & 5.99 & 0.99 & 0.46 \\
\hline & $\mathrm{m}[\mathrm{d}][\mathrm{h}][\mathrm{i}][\mathrm{j}]$ & 0.01 & 3.84 & 1.00 & 0.01 \\
\hline & $\mathrm{m}[\mathrm{d}][\mathrm{h}][\mathrm{i}][\mathrm{l}]$ & 0.01 & 3.84 & 1.00 & 0.01 \\
\hline \multirow[t]{6}{*}{ US28 x 625-3 } & $\mathrm{m}[\mathrm{d}][\mathrm{h}]$ & 6.01 & 7.81 & 0.93 & 2.00 \\
\hline & $\mathrm{m}[\mathrm{d}][\mathrm{h}][\mathrm{i}]$ & 2.94 & 5.99 & 0.96 & 1.47 \\
\hline & $\mathrm{m}[\mathrm{d}][\mathrm{h}][\mathrm{j}]$ & 5.68 & 5.99 & 0.93 & 2.84 \\
\hline & $\mathrm{m}[\mathrm{d}][\mathrm{h}][\mathrm{l}]$ & 5.68 & 5.99 & 0.93 & 2.84 \\
\hline & $\mathrm{m}[\mathrm{d}][\mathrm{h}][\mathrm{i}][\mathrm{j}]$ & 0.07 & 3.84 & 0.99 & 0.07 \\
\hline & $\mathrm{m}[\mathrm{d}][\mathrm{h}][\mathrm{i}][\mathrm{l}]$ & 0.07 & 3.84 & 0.99 & 0.07 \\
\hline \multirow[t]{6}{*}{ US28 x 88B147 } & $\mathrm{m}[\mathrm{d}][\mathrm{h}]$ & 6.31 & 7.81 & 0.65 & 2.10 \\
\hline & $\mathrm{m}[\mathrm{d}][\mathrm{h}][\mathrm{i}]$ & $6.30^{*}$ & 5.99 & 0.66 & 3.15 \\
\hline & $\mathrm{m}[\mathrm{d}][\mathrm{h}][\mathrm{j}]$ & 4.66 & 5.99 & 0.75 & 2.33 \\
\hline & $\mathrm{m}[\mathrm{d}][\mathrm{h}][1]$ & 4.66 & 5.99 & 0.75 & 2.33 \\
\hline & $\mathrm{m}[\mathrm{d}][\mathrm{h}][\mathrm{i}][\mathrm{j}]$ & 0.05 & 3.84 & 0.99 & 0.05 \\
\hline & $\mathrm{m}[\mathrm{d}][\mathrm{h}][\mathrm{i}][\mathrm{l}]$ & 0.05 & 3.84 & 0.99 & 0.05 \\
\hline
\end{tabular}

${ }_{\mathrm{z}} \mathrm{m}=$ midparent, $[\mathrm{d}]=$ additive, $[\mathrm{h}]=$ dominance, $[\mathrm{i}]=$ additive $\times$ additive, $[\mathrm{j}]=$ additive $\times$ dominance, and $[1]=$ dominance $\times$ dominance .

* Significant at $P \leq 0.05$. Models significant at $P \leq 0.05$ deviate from expectations and are rejected.

$\mathrm{F}_{2}: \mathrm{n}=\left\{\left(\mathrm{P}_{1}-\mathrm{P}_{2}\right)^{2}[1.5-2 \mathrm{~h}(1-\mathrm{h})]\right\} /\left\{8\left[\mathrm{~V}_{\mathrm{F} 2}-\left(\mathrm{V}_{\mathrm{P} 1}+\mathrm{V}_{\mathrm{P} 2}+2 \mathrm{~V}_{\mathrm{F} 1}\right) / 4\right]\right\}$ where $h=\left(\mathrm{F}_{1}-\mathrm{P}_{2}\right) /\left(\mathrm{P}_{1}-\mathrm{P}_{2}\right) . \mathrm{P}_{1}, \mathrm{P}_{2}, \mathrm{~V}_{\mathrm{Pl}}, \mathrm{V}_{\mathrm{P} 2}, \mathrm{~V}_{\mathrm{F} 1}, \mathrm{~V}_{\mathrm{B} 1}, \mathrm{~V}_{\mathrm{F} 2}$ are defined above.

\section{Results}

DisEaSE RESPONSE. Anthracnose lesions on inoculated fruit of line 115-4 had a mean diameter of $1.4 \mathrm{~mm}$ (Table 1, Fig. 1). Plants exhibited wild growth habit, namely small fruit produced on large, indeterminate plants. Line 625-3 produced fruit intermediate in size to $115-4$ and $88 \mathrm{~B} 147$ and exhibited indeterminate plant habit. Lesions on inoculated fruit of 625-3 were larger than those observed on 115-4 but still quite small relative to the susceptible cultivar US28 (Table 1, Fig. 1). Line 88B147 was compact, determinate in plant habit, and produced larger fruit relative to those described for 115-4 and 625-3. Anthracnose lesions observed on 88B147 were considerably larger than those on fruit of 115-4 and 625-3 (Table 1, Fig. 1). Correlations between fruit size and lesion diameter were small and generally nonsignificant in $F_{1}, F_{2}$, and backcross generations of the three populations developed (Table 1).

Heritability. Broad sense heritability values $(\mathrm{H})$ for anthracnose resistance were moderate in value for populations developed from crosses with the two more resistant parents, 115-4 and 625-3, and lower in the population that originated from the cross between the comparatively less resistant parent 88B147 and US28 (Table 2). Narrow sense heritability $\left(h^{2}\right)$ values declined with decreasing degree of anthracnose resistance in the resistant parent used to develop each of the three populations (Table 2). Narrow sense heritability declined nearly $50 \%$ in the US $28 \times 88 \mathrm{~B} 147$ cross relative to the US28 $\times 115-4$ cross.

GENETIC EFFECTS. Two methods of analysis were utilized to evaluate gene action for anthracnose resistance in the three populations developed. The first method, generation means analysis, produced a range of genetic models that described additive and dominance effects and digenic interactions (Table 3). Based on chisquare analysis, a simple additive dominance model $\mathrm{m}[\mathrm{d}][\mathrm{h}]$ was adequate to describe gene action in each of the three mating series.
Significant additive effects [d] in the additive dominance model were observed for populations derived from US28 $\times 115-4$ and US28 $\times 625-3$, but not in the populations derived from the cross of US28 x 88B147 (Table 2). Dominance effects [h] were nonsignificant in all cases. Addition of additive $\times$ additive [i], additive $\times$ dominance $[j]$, or dominance $\times$ dominance [1] interactions alone to produce four parameter models generally provided only marginal improvements to model $R^{2}$ values for the respective populations and decreased the precision with which additive and dominance effects were estimated as evidenced by increased error variance. In five parameter models with two interaction components, error variances were reduced relative to the additive dominance models and higher chi-square probabilities were generally observed, but improvement of $R^{2}$ estimates were minor, with the exception of populations from the US28 x 88B147 mating series.

A second method to study the nature of genetic effects described by Burton (1951) compared theoretical arithmetic and geometric means with the observed $F_{2}$ means. Close agreement between observed and calculated arithmetic means suggested that additive gene action influenced anthracnose resistance. Observed $\mathrm{F}_{2}$ means for anthracnose lesion diameter were also in good agreement with calculated geometric $\mathrm{F}_{2}$ means, suggesting that nonadditive effects also contributed to the observed variation. Consistent with the genetic effects derived using the joint scaling tests of Mather and Jinks (1982), estimates for the degree of dominance were small.

GENE NUMBER. The $F_{2}$ and backcross generations of the three mating series exhibited continuous distributions for fruit lesion diameter (Fig. 1). In the absence of a large environmental influence on lesion size, the frequency distributions suggested multigenic control of anthracnose resistance. The number of loci or effective factors $(\mathrm{n})$ influencing anthracnose resistance in backcross populations were consistently greater than those estimated in $\mathrm{F}_{2}$ populations (Table 2). The number of genetic factors segregating for anthracnose resistance ranged from a high of 3.3 in the backcross population developed from a cross with the highly resistant, but unadapted, line 115-4 and decreased to a low of 0.6 in the $F_{2}$ population developed from a cross with the advanced large fruited 
breeding line 88B147. Estimated values of $\mathrm{n}$ for line $625-3$ were intermediate to those estimated for lines 115-4 and 88B147.

\section{Discussion}

Measurement of anthracnose lesion diameters clearly demonstrated increasing susceptibility to anthracnose with increasing adaptation of the lines for commercial use and the degree of departure from line 115-4. Close linkage between genes which influence advantageous traits of interest such as crop quality components or disease resistance and genes with negative horticultural influences such as decreased yield or small fruit size often hinder transfer of beneficial characters to elite breeding materials and cultivars with the intensity with which they are expressed in unadapted donor parents. The difficulty experienced in transferring high levels of anthracnose resistance from small-fruited PI lines to large fruited materials suggested a possible linkage between anthracnose resistance and fruit size. In previous studies which attempted to introgress anthracnose resistance from highly resistant, smallfruited accessions into large-fruited genotypes, fruit size in advanced generations was noted to stabilize at a smaller than desirable commercial size while the level of resistance was considerably less than that observed in the resistant donor parent (Barksdale and Stoner, 1975). In the present study, little or no relationship was observed between fruit size and lesion diameter in the respective populations, suggesting that high levels of anthracnose resistance could be transferred to large-fruited lines.

As expected, broad sense heritability estimates were greater than estimates of narrow sense heritability. The moderate broad sense heritability estimates for anthracnose resistance obtained in populations developed from crosses with the two more resistant lines, 115-4 and 625-3, suggested that good progress could be made in a program to transfer resistance genes. Lower heritability estimates for anthracnose resistance in the population developed from a cross with the large fruited breeding line 88B147 are indicative of the lower level of resistance present in this line. Narrow sense heritability estimates demonstrated that additive genetic effects contributed to the observed resistance. Narrow sense heritability estimates declined coincident with increasing horticultural adaptedness and susceptibility to $C$. coccodes in these populations, suggesting a loss of additive effects and/or increase of epistatic effects. These heritability estimates for resistance to $C$. coccodes are in agreement with those reported for resistance to anthracnose caused by $C$. dematium $(\mathrm{Ng}$ et al., 1990). Although replication over different environments may reduce potential bias in these heritability estimates, a previous study demonstrated that lesion size among tomato genotypes with low to moderate levels of anthracnose resistance varied across years, but relative genotype rankings remained the same and year as well as genotype $\times$ year interactions were nonsignificant (Stommel and Haynes, 1998). Because different samples of annual plants must be used in different environments, Warner's estimate of narrow sense heritability does not limit potential environmental bias (Nyquist, 1991).

Genetic models of varying complexity were evaluated to assess the genetic effects contributing to anthracnose resistance. Using the criteria of Mather and Jinks (1982), a simple additive dominance model, $\mathrm{m}[\mathrm{d}][\mathrm{h}]$, was chosen as the best fit model for populations developed from crosses of lines 115-4, 625-3, and 88B147 with the susceptible cultivar US28. Genetic variance for anthracnose resistance derived from PI 272636 was primarily additive. Nonsignificant additive genetic effects in the US28 $\times 88$ B147 series may be attributed to sampling error which negatively affects the precision with which small genetic effects are estimated (Cassol and St. Clair, 1994).

Evaluation of genetic effects by comparison of observed and theoretical $\mathrm{F}_{2}$ generation means (Burton, 1951) demonstrated that additive effects contributed to the observed genetic variation for anthracnose resistance. This is consistent with results of the joint scaling tests. In contrast with joint scaling tests, $\mathrm{F}_{2}$ means comparison also suggested that nonadditive effects may be important. We may consider the latter means comparison test to be a less rigorous evaluation of genetic effects since it relies on a simple comparison of observed and calculated $\mathrm{F}_{2}$ means. The potential contribution of nonadditive effects in this germplasm for anthracnose resistance cannot be entirely discounted, however. Genetic variance for $C$. coccodes resistance in tomato derived from $L$. pimpinellifolium (Jusl.) Mill. was reported to be primarily nonadditive (Robbins and Angell, 1970a). Resistance to C. dematium was best explained by additive effects, although dominance and epistatic effects were also present (Ng et al., 1990). Identification of molecular markers linked to loci with digenic or higher order interactions in our populations may justify a more complex model to explain gene action.

The formulas described by Petr and Frey (1966) and Kotecha and Zimmerman (1978) provide an estimate of the overall phenotypic degree of dominance, but are not informative regarding individual loci which contribute to a quantitatively inherited trait. Even when individual genes exhibit pronounced dominance, if their directions of dominance differ, the observed degree of dominance may be small or even zero.

Additive effects [d] decreased with increasing anthracnose susceptibility and the relative stage of advancement for commercial use of the resistant parent. Similarly, estimates of gene number or effective factors which contributed to anthracnose resistance declined with increasing anthracnose susceptibility and commercial adaptation of the resistant parent. The accuracy of these estimates of the number of loci or effective factors which influence a trait rely on the assumptions that there is no nonallelic interaction, parents are at opposite phenotypic extremes, all loci make equal contributions, and linkage between genes is absent (Wright, 1968). Violation of any of these assumptions results in an underestimation of $n$. The assumption that all loci make equal contributions to the phenotype is quite improbable. Likewise, because varying degrees of linkage between loci influencing resistance cannot be discounted, the estimates obtained herein reflect minimum estimates of the number of loci or effective factors involved. The inbred-backcross method of estimating gene number has been regarded as a more precise method of estimating gene number (Mulitze and Baker, 1985). It is probable that the inbred-backcross method, however, also underestimates gene number (Rau et al., 1994). The puncture inoculation technique utilized in the present study to evaluate anthracnose resistance may be severe enough to overcome resistance loci with small effects, resulting in their exclusion from the estimate. Nonwounding inoculation techniques for evaluation of anthracnose resistance are less severe relative to the puncture inoculation technique and result in slower growing lesions in lines with lower levels of resistance, such as $88 \mathrm{~B} 147$. Although less reliable, nonwounding inoculation techniques, together with management of environmental effects, may provide a means to recover loci with small effects.

Estimates of narrow sense heritability, the degree of dominance and number of effective factors, together with the best fit genetic models and $\mathrm{F}_{2}$ means comparison, provide evidence of a loss of additive effects for anthracnose resistance with increasing adaptedness and anthracnose susceptibility of the resistant parent. 
The contribution of additive effects to anthracnose resistance suggests that high levels of resistance may be attainable in adapted lines if individual genes which influence resistance can becombined in inbred backcross and pedigree breeding programs. Progress in combining resistance loci would be maximized by minimizing the influence of potential epistatic effects which might occur in the respective populations. Intermating of resistant early generation selections may permit recombination of desirable resistance genes and maximize subsequent breeding progress in developing resistant lines.

\section{Literature Cited}

Barksdale, T.H. 1972. Resistance in tomato to six anthracnose fungi. Phytopathology 62:660-663.

Barksdale, T.H., J.M. Good, and L.L. Danielson. 1972. Tomato diseases and their control. U.S. Dept. Agr. Hdbk. 203.

Barksdale, T.H. and E.J. Koch. 1969. Methods of testing tomatoes for anthracnose resistance. Phytopathology 59:1373-1376.

Barksdale, T.H. and A.K. Stoner. 1975. Breeding for tomato anthracnose resistance. Plant Dis. Rpt. 59:648-652.

Burton, G.W. 1951. Quantitative inheritance in pearl millet (Pennisetum glaucum). Agron. J. 43:409-417.

Byrne, J.M., M.K. Hausbeck, and R.X. Latin. 1997. Efficacy and economics of management strategies to control anthracnose fruit rot in processing tomatoes in the midwest. Plant Dis. 81:1167-1172.

Cassol, T. and D.A. St. Clair. 1994. Inheritance of resistance to blackmold (Alternaria alternata (Fr.) Keissler) in two interspecific crosses of tomato (Lycopersicon esculentum $\times$ L. cheesmanii f. typicum). Theor. Appl. Genet. 88:581-588.

Dillard, H.R. and A.C. Cobb. 1998. Survival of Colletotrichum coccodes in infected tomato tissue and in soil. Plant Dis. 82:235-238.

Globerson, D., A. Genizi, and J.E. Staub. 1987. Inheritance of seed weight in Cucumis sativus (L.) var. sativus and var. hardwickii (Royle) Kitamura. Theor. Appl. Genet. 74:522-526.

Illman, W.I., R.A. Ludwig, and J. Farmer. 1959. Anthracnose of canning tomatoes in Ontario. Can. J. Bot. 37:1237-1246.
Kotecha, A. and L.H. Zimmerman. 1978. Inheritance of seed weight, pappus, and striped hull in safflower species. Crop Sci. 18:999-1003. Mather, K. 1949. Biometrical genetics. 1st ed. Dover Publications, London.

Mather, K. and J.L. Jinks. 1982. Biometrical genetics. 3rd ed. Chapman and Hall, London.

Mulitze, D.K. and R.J. Baker. 1985. Evaluation of biometrical methods for estimating the number of genes: 1. Effect of sample size. Theor. Appl. Genet. 69:553-558.

Ng, T., A.N. Miller, and T.H. Barksdale. 1990. Inheritance of tomato resistance to Colletotrichum dematium. HortScience 25:562-564.

Nyquist, W.E. 1991. Estimation of heritability and prediction of selection response in plant populations. Crit. Rev. Plant Sci. 10:235-322.

Petr, F.C. and K.J. Frey. 1966. Genotypic correlations, dominance, and heritability of quantitative characters in oats. Crop Sci. 6:259-262.

Rau, G.A., C.E. McCulloch, and M.A. Mutschler. 1994. Evaluation of parental-type classification for the inbred-backcross method of estimating gene number. J. Hered. 85:105-111.

Robbins, M.L. and F.F. Angell. 1970a. Tomato anthracnose: Inheritance of reaction to Colletotrichum coccodes in Lycopersicon spp. J. Amer. Soc. Hort. Sci. 95:469-471.

Robbins, M.L. and F.F. Angell. 1970b. Tomato anthracnose: A hypodermic inoculation technique for determining genetic reaction. J. Amer. Soc. Hort. Sci. 95:118-119.

Sanogo, S., S.P. Pennypacker, R.E. Stevenson, and A.A. MacNab. 1997. Weather variables associated with infection of tomato fruit by Colletotrichum coccodes. Plant Dis. 81:753-756.

Stevenson, W.R., G.E. Evans, and T.H. Barksdale. 1978. Evaluation of tomato breeding lines for resistance to fruit anthracnose. Plant Dis. Rpt. 62:937-940.

Stommel, J.R. and K.G. Haynes. 1998. Inheritance of resistance to anthracnose caused by Colletotrichum coccodes in tomato. J. Amer. Soc. Hort. Sci. 123:832-836.

Warner, J.N. 1952. A method for estimating heritability. Agron. J. 44:427-443.

Wright, S. 1968. Evolution and genetics of populations. The Univ. of Chicago Press, Chicago. 